\title{
A COLIGAY E AS MEMÓRIAS DOS TORCEDORES DO GRÊMIO
}

\author{
THE COLIGAY AND THE MEMORIES OF THE GRÊMIO FANS
}

\author{
Gustavo Andrada Bandeira ${ }^{1}$, Fernando Seffner ${ }^{2}$ \\ 1 Universidade Federal do Rio Grande do Sul, Escola de Administração, Brasil, e-mail: \\ gustavoabandeira@yahoo.com.br \\ 2 Universidade Federal do Rio Grande do Sul, Programa de Pós-Graduação em Educação, Brasil, e- \\ mail: fernandoseffner@gmail.com
}

\author{
ARTICLE INFO \\ Article history: \\ Received 2019-10-21 \\ Accepted 2020-01-03 \\ Available online 2020-02-20
}

Palavras-chave: Coligay. Torcida. Futebol. Homofobia.

Keywords: Coligay. Fans. Football. Homophobia.

RESUMO. Diferentes manifestações associadas ao futebol produzem representações de gênero e sexualidade dentro de uma lógica heteronormativa, machista e homofóbica. No Brasil, as manifestações verbais realizadas pelos torcedores nos estádios passaram a ser colocadas em questão. Em 2016, a FIFA impôs sanções pecuniárias à CBF pelo comportamento dos torcedores durante jogos das eliminatórias para a Copa do Mundo de 2018. No Grêmio podemos entender que vivemos certa "ressurreição" da Coligay, torcida homossexual do clube entre o final da década de 1970 e início de 1980. Não chegamos a vislumbrar a hipótese de seu retorno à Arena neste momento, entretanto um livro e um curta metragem já foram produzidos sobre ela e o clube "oficializou" sua existência em seu novo museu inaugurado no início de 2016. Através de diálogos com pequenos grupos de torcedores no estádio, no dia dos jogos, buscamos saber como estes indivíduos percebem, enquanto sujeitos torcedores, esse ressurgimento da Coligay. Os embates do presente produzem ressignificações acerca do passado das torcidas e da história dos clubes, em particular acionando os marcadores gênero e sexualidade.

ABSTRACT. Football is a gender-building arena. During these battles, the construction of meaning associated with sports reproduce representations of gender and sexuality inside a logic that is hetero-normative, male chauvinist and homophobic. In Brazil, the verbal expressions, made in many sports venues by groups of fans, have been put into question. In 2016, the FIFA imposed pecuniary sanctions against CBF for fans' behavior during the 2018 World Cup qualification for chantics perceived as being homophobic. We can understand a certain "resurrection" of Grêmio's Coligay, its group of gay fans that existed between the late 1970's and the early 1980's. We can't see it returning to Grêmio's Arena at this moment, but a book and a short documentary were made about it, and the club itself has "officialized" Coligay's existence in its new museum, opened in early 2016. Through dialogues recorded with small groups of fans in the stadium, during fieldwork, at gameday, we directly asked how they perceived, as fans, Coligay's resurrection. Today's battles create new understandings of the fans' past, specially in the areas of gender and sexuality.

\section{Futebol e seus estádios generificados}

Existe certo consenso de que os esportes, como os conhecemos, são um fenômeno próprio da modernidade. Os esportes modernos, seja em sua prática ou em sua fruição, acabam sendo um espaço privilegiado de investigação sobre as masculinidades. Apesar de 
poder ser assistido e praticado por meninos, meninas, homens, mulheres cis e, cada vez mais por sujeitos transgêneros ou não binários, ainda existem hierarquias de gênero bastante marcadas com conteúdos específicos, abordando não apenas a predominância da masculinidade como representação legítima no espaço do futebol de espetáculo, como limitando as possibilidades de vivências dessa masculinidade.

O contexto de produções de masculinidade dos estádios de futebol é marcado por um forte heterossexismo e por manifestações constantes que desvalorizam masculinidades que fujam de representações heteronormativas, "a heterossexualidade, mais do que tomada como norma, é enfatizada como valor" (ANJOS, 2018, p. 18). Nos estádios, também existe de forma um tanto permanente, certa promessa de confrontos físicos. Curiosamente, neste espaço, também aparecem grandes manifestações públicas de sentimentos e de afetos masculinos. Nos estádios de futebol, demonstrações de afetos entre homens parecem não causar o mesmo impacto de reprovação que em outras esferas de nossa cultura heteronormativa. É possível entender

(...) essa aparente contradição como mais um indício de que as manifestações desenvolvidas no contexto da arquibancada são interpretadas como performances, inseridas num contexto ritual específico do jogo de futebol. Assim, as fugas à masculinidade normativa seriam bem recebidas quando figuram no tempo-espaço do jogo, mas não fora dele (ANJOS, 2018, p. 221).

Um dos principais conteúdos do currículo de masculinidade e do torcer é a constante desvalorização das práticas homoeróticas, especialmente aquelas associadas à passividade. Esse currículo de masculinidade e do torcer "aponta para processos educativos, quase sempre não formais, que permitem que os sujeitos se coloquem em determinada comunidade afetiva, em determinado grupo identitário, dentro de uma doutrina" (BANDEIRA, 2010, p. 345). A sexualidade aparece como um conteúdo definitivo para a marcação dos sujeitos possíveis ou impossíveis nos estádios de futebol. A relação se estabelece entre um 'nós', associado a masculinidades heterossexuais, viris e guerreiras, diferente 'deles', mais próximos das masculinidades não heterossexuais e das feminilidades (BANDEIRA, 2009).

Os esportes em geral, e o futebol em específico, acabam trabalhando fortemente na circulação e na produção de valores e de representações associados a masculinidades. Eles podem ser lidos como uma das instituições generificadas e androcêntricas de nossa cultura (MÜHLEN; GOELLNER, 2012). Nos estádios de futebol, os sujeitos acabam sendo constituídos por uma série de elementos valorizados dentro da 'cultura masculina', "a competição, a forte apreensão relativamente à demonstração de vulnerabilidade, o controle

\footnotetext{
${ }^{1}$ Utilizamos aspas simples no texto quando procuramos fazer algum destaque ou utilizar as palavras com outros sentidos que não os convencionais; o uso de aspas duplas aparece quando utilizamos citações, palavras e/ou expressões de outros autores.
} 
dos sentimentos e a homofobia constituem os elementos que modelam o jeito de ser homem" (BORRILLO, 2010, p. 89). A associação entre esporte e construções de masculinidade é uma possibilidade de visualizar de que forma o gênero funciona como um atravessador das instituições. Tal qual na relação com aprendizagens sobre o uso e funcionamento de máquinas marcados por gênero, "quanto mais um homem souber sobre carros, mais estará dentro do que é destinado ao espaço masculino, mais será propriamente 'homem"' (SEFFNER; FIGLIUZZI, 2011, p. 55), o que está em questão quando se aprende a jogar, ou mesmo a torcer, não são apenas as melhores maneiras de executar essas práticas, mas se está ingressando em uma instituição repleta de significados de gênero, sexualidade e outros conteúdos culturais.

Os estádios de futebol são espaços singulares para a investigação de masculinidades. Diferentes discursividades no esporte carregam conteúdos de uma masculinidade bastante fixa e tradicional. Ao mesmo tempo, estar situado em um coletivo de homens impregnado pela sensibilização das emoções pode permitir comportamentos um tanto transgressores dentro da lógica heteronormativa de nossa cultura. Neste trabalho nos propomos a discutir, a partir de certo ressurgimento da Coligay na historiografia do Grêmio Foot-Ball Porto Alegrense ${ }^{2}$, como os torcedores dialogam com a memória sobre uma torcida homossexual.

\section{Desnaturalização de algumas práticas torcedoras}

A Copa do Mundo da Fédération Internationale de Football Association (FIFA) de 2014, realizada no Brasil, auxiliou, em alguma medida, a catalisar um processo de reforma dos estádios e da elitização de seus públicos. Algumas formas de materialização dos já existentes processos de 'modernização' poderiam ser visualizadas nas novas arenas edificadas nesse período. A competição organizada pela FIFA poderia ser tomada "como fenômeno acelerador de tendências neoliberais já em curso no futebol brasileiro; particularmente, como evento que inscreverá em nosso território uma nova paisagem futebolística, por meio de novas 'arenas'” (MASCARENHAS, 2014, p. 210). Junto com um maior controle e disciplinamento dos corpos e do aumento do preço das entradas, diferentes pedagogias culturais apareceram no contexto mais amplo do futebol nacional e internacional, apresentando problemas até então quase esquecidos neste ambiente.

O ambiente dos estádios de futebol, no Brasil, "são percebidos como lugares em que as emoções são consideradas manifestações não apenas aceitáveis, mas até exigidas" (COSTA, 2014, p. 188). Essas emoções aceitas e exigidas acabaram autorizando um ambiente com presença significativa de insultos que, por serem produzidos nesse espaço distinto do cotidiano, não carregariam as mesmas sanções morais e mesmo estéticas em

${ }^{2}$ De agora em diante, Grêmio. 
relação a outros espaços. Boa parte dessas jocosidades em disputa nos estádios mostra como essas relações funcionam "enquanto dispositivos de controle de uma norma de gênero pautada no heterossexismo e na masculinidade normativa" (ANJOS, 2018, p. 238). Invadidos por discursos que se aproximavam de demandas dos direitos humanos, a elitização e a contenção dos públicos torcedores também vieram acompanhadas de um olhar mais atento ao que os torcedores dizem, gritam e cantam.

Diferentes proibições sobre manifestações de torcedores têm aparecido nos estádios de futebol. A FIFA se posicionou favorável à diminuição dos insultos machistas e homofóbicos nos estádios de futebol. A federação chegou a punir, no segundo semestre de 2015, seis federações por cânticos, entendidos por ela, como homofóbicos ${ }^{3}$. A Confederação Brasileira de Futebol (CBF) foi punida pela primeira vez em 20 mil francos após a partida contra a Colômbia pelas Eliminatórias para a Copa do Mundo de 2018, realizada no dia 06 de setembro de 2016. As infrações nos estádios brasileiros continuaram gerando novas multas.

Junto a isso, podemos entender que, especificamente na torcida do Grêmio - em alguma medida, para acalmar as denúncias de racismo sofridas pelo clube ${ }^{4}$-, vivemos certa ressurreição da Coligay, torcida homossexual do clube entre o final da década de 1970 e início de 1980. Neste momento, ainda não parece possível vislumbrar a hipótese de seu retorno à Arena. Entretanto, um livro, um curta metragem e uma tese de doutorado já foram produzidos sobre ela. O próprio clube 'oficializou' a existência da torcida em seu museu, inaugurado no início de 2016 em seu novo estádio.

É nesse espectro amplo de uma lógica de 'modernização' do futebol e de suas praças esportivas, catalisado no Brasil a partir da Copa de 2014, que procuramos olhar como os torcedores do Grêmio, 'alfabetizados' para o torcer no antigo estádio Olímpico dialogam com esse 'retorno' da torcida homossexual do clube para sua historiografia. De modo mais explícito: tentamos observar como esses homens que continuam aprendendo a ser torcedores e a serem masculinos são atravessados por normativas de respeito ou, no mínimo, de não agressão a sujeitos homossexuais potencializadas com essa 'ressurreição da Coligay'.

\section{Estratégias metodológicas 5}

Este trabalho está inserido no 'indisciplinado' campo das ciências humanas. Essa indisciplina "não significa recusar o rigor do pensamento, pelo contrário, apresenta a

\footnotetext{
${ }^{3}$ Disponível em: http://www.sul21.com.br/jornal/fifa-multa-federacoes-de-futebol-por-cantos-homofobicos-de-torcida/. Acesso em $17 / 01 / 2017$, às $15 \mathrm{~h} 36$.

${ }^{4}$ Ver BANDEIRA; SEFFNER, 2016.

${ }^{5}$ Este artigo utiliza dados produzidos para uma tese de doutoramento que não passou por comitês de ética em pesquisa por duas circunstâncias. A primeira delas foi sua realização já estar em andamento antes da aprovação da Resolução $\mathrm{N}^{\circ} 510$, de 07 de abril de 2016 . Apesar disso, optamos por analisar as regras da referida resolução e entendemos que os dados produzidos em nosso trabalho poderiam ser mais bem entendidos como pertencendo ao conjunto de "pesquisa de opinião pública com participantes não identificados", que segundo a Resolução estariam dispensados de avaliação pelo sistema CEP/CONEP.
} 
possibilidade de não ficar a crítica no lugar concluso e fechado, para assim viajar e viajar-se além do disciplinado" (CANEVACCI, 2013, p. 12). Essa possibilidade de viajar para além do disciplinado, entretanto, também exige que os rumos traçados durante o percurso sejam devidamente explicitados. Nosso fazer científico não apresenta álibi, "não se apresenta o discurso do método singular como seu fundamento, mas as escolhas éticas e estéticas do pesquisador que se reinventa, bem como à realidade investigada no próprio processo de pesquisar" (ZANELLA, 2013, p. 21).

Para a produção do material empírico acabamos optando por realizar curtas entrevistas, mais bem entendidas como pequenos diálogos, com diferentes torcedores, para verificar como eles produziam narrativas a partir de suas inserções e distintas apropriações nesse novo espaço para o torcer. Tentamos escutá-los, também, sobre de que maneira eles foram interpelados pelo currículo de torcedor de futebol e de masculinidade atravessados pelos conteúdos que acabavam por mobilizar as condutas dos torcedores do Grêmio.

Uma interpelação é, pois, um chamamento, um enunciado que convoca o sujeito o qual pode ou não assumir a convocação. Seria como se alguém dissesse "ô baixinho" e o cara se virasse e respondesse: "Quem? Eu?", reconhecendo-se de algum modo naquela interpelação e assumindo-se como tal (LOURO, 2016, p. 271).

A aposta por esses diálogos se deu a partir do entendimento que as narrativas produzidas pelos sujeitos permitiram acessar diferentes tentativas de dar inteligibilidade às práticas desenvolvidas por esses atores.

Os antigos estádios de futebol e as novas arenas permitem que sujeitos com trajetórias de vida distintas frequentem os mesmos espaços. Interrogar diferentes sujeitos individualmente, ou em seus pequenos grupos de sociabilidade, possibilitou ampliar o número de narrativas e verificar como os currículos de masculinidade e de torcedores de futebol significaram para distintos sujeitos com que efeitos, reforços, dispersões, contradições... Procuramos observar de que forma certas memórias apareceram de modo mais significativo para os sujeitos que responderam afirmativamente essa interpelação enquanto sujeitos masculinos e torcedores de futebol. Cabe fazer uma pequena observação sobre o entendimento de memória:

(...) a memória, que implica reconhecer informações como sendo informações sobre o passado, precisa ser assumida como processo ativo de construção que se faz no presente e para atender a interesses do presente. Não se copia, nem se resgata, nem se descobre, nem se desvenda o passado, mas se constrói o passado. (...). É para o presente e no presente que se constrói a memória (SEFFNER, 2002, p. 370).

A aposta em conversas com pequenos grupos também acabou permitindo que as falas não acabassem restringidas apenas por nossa presença. A presença de um amigo, irmão, pai ou filho também autorizava determinadas participações e, pelo contexto de sociabilidade em 
que foram realizadas, também nos permitiu participar do local de socialização dos torcedores e não fazer com que eles participassem de uma 'cena de pesquisa' mais formalmente apresentada.

\title{
4. A Coligay e as memórias dos torcedores do Grêmio
}

\begin{abstract}
A Coligay é a mais importante Torcida Organizada (TO) da história brasileira até o presente, para dizer o mínimo. Não foi a pioneira, nem a maior, tampouco a mais longeva (...). A Coligay foi única, simplesmente, e segue sendo. Em muitos aspectos esta torcida se encaixa na classificação usual de "torcida organizada", mas sob outros ela é diferente, por isso the cabe um lugar de destaque na história das práticas torcedoras (DAMO, 2018).
\end{abstract}

Dentro das diferentes disputas por significados sobre as práticas torcedoras nos estádios foi possível constatar certo 'retorno' da Coligay na memória coletiva dos torcedores do Grêmio. A Coligay reuniu entre o final da década de 1970 e o início dos anos 1980 um grupo de torcedores identificados como homossexuais que realizaram variadas performances no estádio Olímpico e, também, em outros estádios do Rio Grande do Sul. O que chamamos de retorno da Coligay se dá não apenas pelos materiais que passaram a ser produzidos sobre ela: um livro (GERCHMANN, 2014), um média-metragem ${ }^{6}$ e uma tese de doutorado (ANJOS, 2018), mas, especialmente, por sua presença no Memorial Hermínio Bittencourt, na Arena do Grêmio, inaugurado em princípios de 2016.

Trabalhos acadêmicos que tratavam sobre a constituição de masculinidades nos estádios de futebol em Porto Alegre (BANDEIRA, 2009) ou sobre o pertencimento clubístico dos torcedores do Grêmio (DAMO, 1998) não fizeram nenhuma menção a essa torcida. Em alguma medida, seria possível questionar se a Coligay não fazia parte do currículo de masculinidades e do torcer durante as últimas décadas?

Nos parece equivocado entender que a Coligay não fazia parte do currículo de masculinidade dos torcedores de estádio, especialmente em Porto Alegre e na torcida do Grêmio. Dentro do dispositivo pedagógico dos estádios de futebol, a Coligay acabou ocupando um lugar de destaque. O lugar do apagamento, do desconhecimento, da ignorância.

\begin{abstract}
Não se deve fazer uma divisão binária entre o que se diz e o que não se diz; é preciso tentar determinar as diferentes maneiras de não dizer, como são distribuídos os que podem e os que não podem falar, que tipo de discurso é autorizado ou que forma de discrição é exigida a uns e outros (FOUCAULT, 2005, p. 30).
\end{abstract}

Entretanto, nesse jogo de visibilidade e invisibilidade, a Coligay passou a disputar um novo lugar durante a segunda década deste século. No início de 2016, foi inaugurado, na

${ }^{6}$ Para o que der e vier dirigido e roteirizado por Pedro Guindani 
Arena do Grêmio, o Memorial Hermínio Bittencourt. Além de bolas, uniformes e troféus, o memorial também conta com painéis em homenagem à torcida e aos torcedores. Um desses painéis é dedicado à Coligay. O painel é intitulado Diversidade da Alegria e apresenta o seguinte texto:

Na cinzenta década de 1970, o Brasil atravessava um dos períodos mais obscuros de sua história, com repressão e censura suprimindo e sufocando as liberdades democráticas. Era preciso ser muito corajoso para expor sua preferência sexual, ainda mais dentro de um estádio de futebol. Mas a torcida Coligay encarou a ditadura e tomou para si o desafio de reerguer o moral do time, que andava para baixo. Vestindo figurino extravagante e ousado de túnicas esvoaçantes, plumas e paetês - tudo em azul, preto e branco, é claro - cerca de 60 rapazes gremistas provaram que o Grêmio é mesmo um clube plural e inovador do país.

Volmar Santos, então gerente da célebre boate Coliseu, de Porto Alegre, foi quem organizou a festa: "Eu queria a torcida incentivando mesmo quando o time não ia bem... Quando parti pra recrutar, pensei em gente como eu!". Cantando, pulando e dançando o tempo todo ao som de sua potente charanga, a Coligay embalava o time e os estádios por onde passava. O que realmente os distinguia era a animação e o bom humor.

O clube acolheu a torcida e esta, além da alegria, trouxe sorte e foi pé quente! Logo, todos os gremistas puderam comemorar o mais festejado título gaúcho da história (1977) e seguiram comemorando, Brasileiro, Libertadores, até a conquista do mundo, em 1983.

A torcida chegou ao fim, pois seu líder, Volmar, retornou naquele ano para sua terra natal, Passo Fundo. Mas a Coligay já havia ajudado a colorir os anos de chumbo.

Nas redes sociais, temos acompanhado algumas manifestações, que ainda não gozam de grande legitimidade nos estádios de futebol, criticando alguns comportamentos de torcedores, especialmente associados ao machismo e à homofobia. Nessas reclamações, a experiência da Coligay é lembrada como um positivo exemplo de experiência transgressora nos estádios de futebol. Procuramos nos diálogos realizados identificar como essa memória ou esquecimento sobre a torcida homossexual do Grêmio era entendida e narrada pelos torcedores do clube.

Existe um conjunto de torcedores que acredita que a presença da Coligay em posição mais central na historiografia do Grêmio poderia ser positiva para o clube. Elano ${ }^{7}$ destacou que "seria bacana para a história e sendo para ajudar o clube e o time tudo é válido" (DC $3^{9}$ ). Sobre a presença da Coligay no Memorial Hermínio Bittencourt, Bruno apontou que "cada um tem a sua opção, a sua raça, então tu não vais mudar o que a gente sente pelo clube. Se for para ser um clube, ter uma história de um clube mais abrangente, mais tolerante, excelente não vai importar em nada, não vai mudar em nada" (DC 19). Neuton entendia que a possibilidade de positivar a história da Coligay e de colocá-la no museu "é uma grande ideia do Grêmio, é muito ousada a curto prazo, é ousada, mas no longo prazo eu acho que vai dar

\footnotetext{
${ }^{7}$ Os nomes dos torcedores com os quais dialogamos foram alterados para manutenção do anonimato.

${ }^{8}$ As falas dos torcedores registradas com o gravador serão destacadas em itálico.

${ }^{9}$ Todas as manifestações dos torcedores compuseram nossos diários de campo. Optamos por utilizar após cada um desses trechos a sigla DC, para diário de campo, e o número do respectivo diário.
} 
um grande resultado porque se tu vês a educação das crianças agora é diferente. Talvez a longo prazo dê bom resultado" (DC 24).

Em diferentes diálogos utilizamos a relação do Sport Club Internacional ${ }^{10}$ com os negros como mito de origem. O principal rival do Grêmio teve uma excelente capacidade de produção de sua vinculação ao popular e, também, aos negros a partir das décadas de 1930 e de 1940 e acaba sendo lido como um clube em que a presença negra se vincula a sua origem. Para os diálogos conseguimos trabalhar razoavelmente bem essa relação como 'mito de origem' do rival. Em um exercício de imaginação, questionamos esses mesmos torcedores para saber se eles entendiam que seria possível o Grêmio realizar uma apropriação semelhante utilizando a Coligay como certo mito de origem para narrar sua história torcedora como mais tolerante. Ângelo afirmou que "possível é, mas eu, particularmente não iria curtir a história do time ser em cima disso aí, não por um preconceito para mim não interessa se é negro, se é branco se é veado, mas... quer vir, vem" (DC 12). Victor entendia que "a positivação da Coligay nunca vai acontecer e como eu tenho filho, eu acho isso bom porque eu não gostaria que meu filho crescesse vendo esse tipo de coisa porque eu sou daqueles que acreditam que homem é homem e mulher é mulher" (DC 18). Edilson respondeu que "quando eu falo com algum outro torcedor esse é um assunto que não gostam como gremista. Se os caras pudessem apagar isso aí poderia passar despercebido, não é um título que a gente gostaria de ter como o primeiro clube a mostrar que não tem preconceito" (DC 21). É interessante que mesmo nesse contexto, Edilson acredita que não existe preconceito contra homossexuais na torcida do Grêmio: "beleza, não há preconceito, mas não precisa fazer uma torcida gay para isso" (DC 21). Essa relação entre a existência ou não de preconceito/violência em relação a torcedores homossexuais também é entendida dessa maneira pelos antigos integrantes da Coligay. Em seu trabalho sobre a torcida, Luiza Aguiar dos Anjos aponta: "Chama atenção o fato da existência de preconceito ser negada pelos ex-componentes da Coligay, mas ao mesmo tempo, de mencionarem situações em que não se sentiam seguros no ambiente futebolístico e o fato de tomarem certas precauções" (2018, p. 119). Adilson achava muito difícil o Grêmio realizar tal apropriação: "eu acho que o clube não se apega tanto como o Inter fez, trouxe. O Grêmio quer se apegar como um clube que a torcida tanto homossexual, negro, branco, todos tenham seus direitos e tenham lugar no estádio sem nenhum preconceito" (DC 24). Jonas creditou a ação a uma estratégia de marketing do clube: "foi uma jogada boa do marketing do Grêmio ter assumido e não fugir do assunto como fugia antigamente" (DC 25). Mesmo reconhecendo a provocação feita pelos rivais, Maylson entendia que "o próprio torcedor do Grêmio nisso aí iria se orgulhar, apesar da 'folgação' eles iriam se orgulhar porque daí iriam tirar um pouco daquela imagem racista que o gremista é e

\footnotetext{
${ }^{10}$ De agora em diante, Internacional.
} 
iriam levar para o outro lado" (DC 26). Maurício manifestou apoio na realização de ações contra a homofobia "a gente sabe que existe, no estádio de futebol o que mais tem é homofobia" (DC 28). Réver entendia que era bem difícil falar. Segundo ele, "o preconceito racista caiu, sei lá, de 100\%, deve ter 1\% de racismo no mundo, digamos assim. Agora, em relação aos gays, em relação ao orgulho do clube, eu não sei se o clube futuramente usaria como marketing do clube a parte da torcida gay" (DC 29). Enquanto gremista, ele acreditava que não faria essa positivação: "eu não tenho nada contra, eu até acho que são torcedores, assim como nós, que tem que participar, mas eu não sei se o clube usaria isso como marketing do clube, enfim, como orgulho" (DC 29).

Uma importante maneira de conhecer a Coligay é o desconhecimento. Em alguma medida, ela se construiu como tema proibido dentro da torcida do Grêmio e uma das formas mais legítimas de se relacionar com a histórica torcida é não conhecê-la. Nesse contexto masculino e heteronormativo, "o lugar do conhecimento mantém-se, com relação à sexualidade, como o lugar do desconhecimento e da ignorância" (LOURO, 2001, p. 30). Alex afirmou saber superficialmente e alegou não ter conhecimento. Ele acreditava que "é um tema pouco explorado" (DC 6). Jean comentava ter "dúvida se a Coligay existiu ou não, mas se tem respeito, sem problema" (DC 6). Além do desconhecimento relatado por alguns dos torcedores, outros mostraram a falta de esforço em buscar maiores informações o que, em alguma medida, poderia ser percebido como um exercício de ignorância deliberado. Everaldo disse que "conhecia por ter ouvido uma reportagem na [Rádio] Gaúcha em que eles explicavam como foi, quando aconteceu, quando inventaram. Eu tinha conhecimento, mas só de ouvir falar" (DC 12). Seu amigo, Matheus, disse que "também, nunca cheguei a ler sobre o assunto, saber exatamente como aconteceu, eu acho que foi mais pela fase da gozação, de escutar rádio e reportagens da Coligay, mas como aconteceu a história realmente eu nunca procurei saber" (DC 12). Matías disse que não tem recordação de ver no estádio "porque comecei a frequentar depois, mas de ver a torcida na televisão eu não tenho recordação, mas eu acho que também essa coisa de mídia tudo é aproveitado" (DC 15). Odacir usou o argumento etário para justificar seu desconhecimento: "não é da minha época, só por falar mesmo e até agora lançou um livro, eu até tinha interesse de ler e é uma coisa mais antiga que ocorreu, mas problema nenhum se brincam e tal, tranquilo" (DC 27). É interessante que esse mesmo argumento etário não aparece quando torcedores comemoram os títulos que não vivenciaram.

Outra forma de acesso à existência da Coligay aparece nas piadas, geralmente realizadas pelos torcedores rivais. Rhodolfo disse: "tive conhecimento muito mais pelas piadas dos outros do que pela história da Coligay" (DC 11). Ângelo afirmou que seu conhecimento da Coligay se dava "pelas 'cornetas' dos colorados, mas graças a Deus eu não participei da torcida [risos dele]' (DC 12). Giuliano afirmou que foi conhecer a torcida através de seu pai: "meu pai é colorado e era o primeiro que sacaneava. Vocês são o único clube do Rio Grande 
do Sul que tem uma torcida gay" (DC 14). Tiago disse já ter ouvido falar da Coligay: "por causa dos colorados que ficaram me corneteando e aí fiquei sabendo da Coligay pelos colorados que conheciam bem a Coligay. Eles conheciam melhor do que os próprios gremistas na realidade" (DC 15). Deivson disse que ouviu sobre a Coligay somente "pelos amigos colorados porque era uma coisa de chacota, mas eu acho que isso não interfere em nada" (DC 19). Ozéia afirmou que seu único conhecimento sobre a Coligay foi produzido "através das piadas dos colorados. Eles se aproveitam como se isso fosse nos ofender. Eu não me sinto ofendido e acho que toda a torcida tem e as pessoas, a sociedade tem que modernizar, tem que respeitar. Cada um é de um jeito" (DC 28). José disse que o conhecimento sobre a Coligay veio "pela corneta, até porque a Coligay surgiu numa época em que não se tinha tanta aceitação nessa questão da homossexualidade e a Coligay, digamos, bateu de frente com coragem e tudo o mais. Só que do outro lado veio a corneta" (DC 33).

Outra forma de relacionamento, ou de não relacionamento, com a Coligay é ignorar a possibilidade de vivências torcedoras distintas. Colocando o "gremismo 11 " como marcador essencial da relação entre os diferentes torcedores, Hernán definiu: "se o cara torce pelo Grêmio e é apaixonado pelo Grêmio, eu não tenho preconceito nenhum, se a pessoa está ali independentemente da cor, da raça que ela tem e gosta do time não tem porque banir essas pessoas do estádio" (DC 7). Kléber disse: "a nossa parte, somos gremistas independentemente de cor, sexo, etnia, qualquer coisa. A gente está junto para empurrar o tricolor" (DC 7). Rhodolfo, em um exercício sobre a interpretação que poderia ser dada em um eventual retorno da Coligay, argumentou: "tu não tens a torcida gay do Grêmio, é uma torcida do Grêmio. Eles são gays, eles são brancos, eles são assados, ok, mas é uma torcida do Grêmio" (DC 11). Ele acreditava que as diferentes identidades são subsumidas ao "gremismo" dentro do estádio: "lá fora eu tenho uma vida, tu tens uma vida, cada um tem sua vida, não vou eu julgar tua vida de acordo com o que eu acho que é certo não. Aqui dentro todo mundo é gremista, são grupos que vão se reunir para torcer a favor do Grêmio" (DC 11). Em alguma medida, uma torcida subordinada ao "torcer a favor do Grêmio", que disfarce ou ignore suas diferenças, poderia ser bem acolhida. Esse não seria o único espaço em que homossexuais 'bem-comportados' teriam mais facilidades em serem 'aceitos'.

De um modo geral, salvo raras exceções, o/a homossexual admitido/a é aquele ou aquela que disfarça sua condição, "o/a enrustido/a". De acordo com a concepção liberal de que a sexualidade é uma questão absolutamente privada, alguns se permitem aceitar "outras" identidades ou práticas sexuais desde que permaneçam no segredo e sejam vividas apenas na intimidade. O que efetivamente incomoda é

\footnotetext{
${ }^{11}$ O termo "gremismo" poderia englobar as características ou qualidades do sujeito torcedor do Grêmio. Ele acaba sendo um marco normativo para as apreciações éticas e estéticas no estádio de futebol. Ele seria o clubismo dos gremistas, entendendo clubismo como "um sistema de representação estruturado, de forma que o indivíduo, ao tornar-se torcedor, é capturado por códigos que orientam seu comportamento e moldam a sensibilidade" (DAMO, 2014, p. 39).
} 
a manifestação aberta e pública de sujeitos e práticas não-heterossexuais (LOURO, 2001, p. 29-30).

Apesar de diferentes trabalhos demonstrarem a constante presença de indivíduos homossexuais nas torcidas e nos estádios (ANJOS, 2018; SILVA JÚNIOR, 2018), existe certo entendimento de que o estádio de futebol possa ser lido como um espaço de reserva masculina heterossexual. Jackson afirmou que "se alguém colocar a faixa ali, 'Coligay', vai existir resistência desse público que frequenta estádio desde muito tempo. Não necessariamente que seja um preconceito, mas vai ter uma resistência. Inclusive eu, vou olhar: pô, veado aí? Sei lá" (DC 11). Everaldo achava muito difícil que a Coligay pudesse retornar ou mesmo ser identificada como motivo de orgulho para torcida do Grêmio, "pela questão do preconceito até aquela coisa que parece que o futebol traz de masculinidade, tu botares ali uma torcida gay eu acho até que iria ferir com o orgulho de muito torcedor" (DC 12).

Ao longo dos diálogos com os torcedores, realizamos um exercício para tentar verificar o que eles pensavam sobre uma eventual possibilidade de retorno da Coligay nas cadeiras da Arena. Hernán acreditava que "não existiria problema algum. Seria inclusive uma mostra de grandeza por parte do time do Grêmio. Seria um tapa de luva na cara de muita gente, mostrando que o futebol é um esporte coletivo, é um esporte que agrega valores e não separa" (DC 7). Os irmãos Fábio e Arthur foram unânimes em acreditar que seria possível a existência de uma torcida homossexual contemporaneamente. Arthur, enfaticamente definiu: "vai acontecer" (DC 9). Fábio afirmou que "hoje mais ainda, o politicamente correto é a aceitação" (DC 9). Sobre um eventual retorno da Coligay, Everaldo afirmou não ter nada contra, mas apontou outros atores como possíveis dificultadores desse retorno: "se quiserem criar o que forem criar, quem frequenta, quem é torcedor, se é homossexual ou não é, não tem diferença, mas eu acho que a torcida Geral do Grêmio'12 ia criar alguma dificuldade, algum preconceito em relação a isso" (DC 12). Rodrigo entendia que, quando o livro foi lançado, "o Grêmio tinha que ter abraçado essa história. Qualquer história ligada ao Grêmio é do Grêmio, faz parte do Grêmio" (DC 14). Victor acreditava que "existem gays nas torcidas de Grêmio e de Internacional, mas eles não se apresentam como tal. Eu acredito que se um grupo de torcedores aparecesse com faixas e bandeiras de uma torcida gay eles seriam facilmente alvo de violência física" (DC 18). Sobre a possibilidade de um eventual retorno da Coligay, Germán argumentou: "eu apoiaria, gostaria, mas eu acho que a reação da torcida, por exemplo, aqui a reação da torcida do Grêmio para uma manifestação a favor da Coligay eu acho que seria reprimida. Iria receber uma opressão por parte da própria torcida" (DC 29). Sobre a possibilidade de uma torcida gay em qualquer estádio no Brasil, Renato disse: "teria a

\footnotetext{
${ }^{12}$ Principal Torcida Organizada do Grêmio.
} 
possibilidade, mas ela seria hostilizada, eu tenho certeza que sim, em qualquer clube, eu tenho certeza que sim" (DC 31).

Em alguma medida, esse retorno da Coligay para a história oficial da torcida do Grêmio acaba atravessando de maneira bastante significativa o currículo de masculinidade dos torcedores gremistas. As formas de relacionamento, a positivação ou a negação da torcida, são múltiplas mostrando como essa pauta ainda ocupa um lugar de estranhamento para os sujeitos que foram interpelados pelo currículo de masculinidade dos torcedores de futebol.

\section{Um breve cenário para as próximas partidas}

A publicação de um livro sobre a Coligay, ainda em 2013, nos chamou a atenção por diferentes motivos. Um deles foi nossa ignorância em relação à torcida sendo investigadores de práticas torcedoras no Grêmio, especialmente vinculadas aos estudos de gênero e sexualidade. Lendo o livro do jornalista gremista, Léo Gerchmann, percebemos uma positivação muito grande da torcida. Sua forma de apoio constante, autofinanciamento e o não envolvimento em brigas poderia ser mais uma forma de pedagogia do torcer, mais uma normativa entre as tantas que apareceram no período pré-Copa do Mundo no Brasil. A positivação da torcida também nos causou surpresa, especialmente pelo esforço histórico do clube e dos demais torcedores em apagarem a existência da Coligay das memórias vinculadas ao Grêmio.

Alguns torcedores positivaram a presença da Coligay, tal qual o jornalista. Para alguns, essa experiência era uma grande demonstração de coragem. Para alguns a Coligay poderia melhorar a imagem do clube e da torcida ao apresentar uma experiência de pluralidade no estádio. A retomada histórica da Coligay poderia ser uma forma de a torcida do Grêmio atuar de maneira politicamente correta. A maioria dos torcedores, entretanto, tinham uma forma distinta de compreensão ou de relacionamento com a Coligay. Alguns lembraram que ela era motivo de chacota para os rivais e estaria sempre presente na rivalidade. Um torcedor afirmou que a maioria dos torcedores não gostam dessa experiência na torcida do Grêmio e preferiam que ela não tivesse existido no clube. Algumas formas de relacionamento com a torcida mostram, também, como o conhecimento sobre esse conteúdo de masculinidade aparece para os sujeitos torcedores. O desconhecimento, ou o conhecimento através das piadas, brincadeiras ou provocações, circunscrevem de forma precisa o lugar que a sexualidade não normativa ainda ocupa no currículo de masculinidade dos torcedores de estádio de futebol.

Durante a abordagem aos sujeitos, realizamos um exercício para tentarmos nos aproximar de como os torcedores entendiam essa presença de uma torcida homossexual na torcida do Grêmio. Tomávamos a presença dos negros na história do Internacional como mito de origem do clube rival. Questionamos se essa retomada da Coligay, que passou a 
frequentar o museu do Grêmio, autorizaria o clube a fazer uma ação semelhante em relação às diversidades sexuais. Alguns torcedores apontaram que essa seria uma estratégia de marketing positiva para tirar um pouco das marcas de torcida preconceituosa que acompanha algumas das representações sobre torcedores do Grêmio. Enquanto torcedores mais sensibilizados às pautas de diferentes minorias apontavam que seria uma questão de tempo e que ocorreria naturalmente - o que também aponta como esse tempo, que nunca é facilmente mensurado, pode nos desobrigar a realizar qualquer outro tipo de ação afirmativa -, outros marcavam que essa existência seria desnecessária ou equivocada. Segundo esse raciocínio, a torcida deveria unir e não separar. No caso da torcida do Grêmio, o único ingrediente que deveria ser levado em consideração seria o "gremismo". Incentivando a equipe e colaborando com o clube, os torcedores homossexuais estariam autorizados a torcer 'conosco', mas sem a necessidade de uma torcida homossexual. Esse "gremismo" era lido nessa chave de inteligibilidade como não possuindo marcadores de masculinidade. Em alguma medida, o currículo de masculinidade dos torcedores de estádio foi bastante competente ao participar da construção de sujeitos generificados que não percebiam os diferentes processos pedagógicos pelos quais tiveram que percorrer para se constituírem enquanto torcedores.

Esse certo retorno do Coligay, que procura sair do ostracismo em que ocupava na historiografia do Grêmio, acaba exigindo algumas medidas do clube que passou a realizar algumas tímidas ações em favor da diversidade sexual. O currículo de masculinidade dos torcedores de estádio parece estar minimamente colocado em questão. Esse reaparecimento da Coligay em conjunto com a elitização dos espaços do torcer e outros episódios que aconteceram nos primeiros anos de funcionamento da Arena do Grêmio acabam por desnaturalizar as práticas torcedoras historicamente vinculadas ao machismo e ao heterossexismo. Parece existir uma disputa por significados das masculinidades torcedoras mais evidente do que aparecia até então. Disputas no presente implicam ressignificações na avalição de momentos do passado. E produzem efeitos concretos nos modos de torcer contemporâneos.

\section{Referências}

ANJOS, Luiza Aguiar do. De "são bichas, mas são nossas" à "diversidade da alegria": uma história da torcida Coligay. Porto Alegre, 2018. Tese (Doutorado em Ciências do Movimento Humano) - Universidade Federal do Rio Grande do Sul.

BANDEIRA, Gustavo Andrada. Um currículo de masculinidades nos estádios de futebol. Revista Brasileira de Educação, v. 15, n. 44, maio/ago., p. 342-51, 2010. 
BANDEIRA, Gustavo Andrada. "Eu canto, bebo e brigo... alegria do meu coração": currículo de masculinidades nos estádios de futebol. Porto Alegre, 2009. Dissertação (Mestrado em Educação) - Universidade Federal do Rio Grande do Sul.

BANDEIRA, Gustavo Andrada; SEFFNER, Fernando. Aranha, macaco e veado: o legítimo e o não legítimo no zoológico linguístico nos estádios de futebol. Movimento, v. 22, n. 3, jul./set., p. 985-998, 2016.

BORRILLO, Daniel. Homofobia: história e crítica de um preconceito. Belo Horizonte: Autêntica Editora, 2010.

CANEVACCI, Mássimo. Colecionadora de perguntas. In: ZANELLA, Andréa Vieira. Perguntar, registrar, escrever: inquietações metodológicas. Porto Alegre: Sulina; Editora da UFRGS, 2013.

COSTA, Leda. 1982: lágrimas de uma geração de ouro. In: CABO, Alvaro do; HELAL, Ronaldo. (Orgs.). Copa do Mundo: comunicação e identidade cultural no país do futebol. Rio de Janeiro: EdUERJ, 2014.

DAMO, Arlei Sander. Coligay - o esplendor recuperado. Ludopédio, 31 de ago. de 2018. Disponível em: https://www.ludopedio.com.br/arquibancada/coligay-o-esplendor-recuperado/. Acesso em 10 jan. 2020.

DAMO, Arlei Sander. O espetáculo das identidades e das alteridades - As lutas pelo reconhecimento no espectro do clubismo brasileiro. In: CAMPOS, Flavio de; ALFONSI, Daniela. (Orgs.). Futebol objeto das ciências humanas. São Paulo: Leya, 2014.

DAMO, Arlei Sander. Para o que der e vier: o pertencimento clubístico no futebol brasileiro a partir do Grêmio Foot-Ball Porto Alegrense e seus torcedores. Porto Alegre, 1998. Dissertação (Mestrado em Antropologia) - Universidade Federal do Rio Grande do Sul.

FOUCAULT, Michel. História da sexualidade I: a vontade de saber. Rio de Janeiro: Edições Graal, 2005.

GERCHMANN, Léo. Coligay: tricolor e de todas as cores. Porto Alegre: Libretos, 2014.

LOURO, Guacira Lopes. Discursos de ódio. In: SEFFNER, Fernando; CAETANO, Márcio. (Orgs.). Discurso, discursos e contra-discursos latino-americanos sobre a diversidade sexual e de gênero. Rio Grande: Editora da FURG; Realize Editora, 2016.

LOURO, Guacira Lopes. Pedagogias da sexualidade. In: LOURO, Guacira Lopes. (Org.). O corpo educado: pedagogias da sexualidade. Belo Horizonte: Autêntica, $2^{\underline{a}}$ ed., 2001.

MASCARENHAS, Gilmar. Entradas e Bandeiras: a conquista do Brasil pelo futebol. Rio de Janeiro: EdUERJ, 2014.

MÜHLEN, Johanna Coelho Von; GOELLNER, Silvana Vilodre. Representações de feminilidades e masculinidades (re)produzidas pelo site Terra. Revista Brasileira de Ciências do Esporte, v. 34, n. 1, jan./mar., p. 165-184, 2012. 
SEFFNER, Fernando. Explorando caminhos no ensino de história local e regional. In: RECZIEGEL, Ana Luiza Setti; FÉLIX, Loiva Otero (Orgs.). RS: 200 anos definindo espaços na história nacional. Passo Fundo: UPF, 2002.

SEFFNER, Fernando; FIGLIUZZI, Adriza. Na escola e nas revistas: reconhecendo pedagogias do gênero, da sexualidade e do corpo. Revista da Faced, n. 19, jan./jun., p. 45-59, 2011.

SILVA JÚNIOR, José Aelson da. Pedagogia do armário: identidade, pertencimento e apropriação do futebol por torcedores homossexuais. Belo Horizonte, 2018. Tese (Doutorado em Estudos do Lazer) - Universidade Federal de Minas Gerais.

ZANELLA, Andréa Vieira. Perguntar, registrar, escrever: inquietações metodológicas. Porto Alegre: Sulina; Editora da UFRGS, 2013. 